\title{
What is the Smallest Zeolite that Could be Synthesized?
}

\author{
Debdas Dhabal, ${ }^{[a]}$ Andressa A. Bertolazzo, ${ }^{[a]}$ and Valeria Molinero*[a]
}

\author{
[a] Debdas Dhabal, Andressa A. Bertolazzo and Valeria Molinero \\ Department of Chemistry \\ University of Utah \\ Salt Lake City, UT 84112, United States of America \\ E-mail: valeria.molinero@utah.edu
}

Supporting information for this article is given via a link at the end of the document.

\begin{abstract}
Zeolites with a few unit cells are promising as catalyst and adsorbents. The quest to synthesize the smallest zeolites has recently resulted in 4 to $8 \mathrm{~nm}$ nanozeolites, about 2 to 4 unit cells, obtained with a smart choice of structure directing agent. These findings pose the question of what is the smallest zeolite that could be obtained by hydrothermal synthesis. Here we address this question using molecular simulations and thermodynamic analysis. The simulations predict that amorphous precursors as small as $4 \mathrm{~nm}$ can crystallize zeolites, in agreement with the experiments. We find that interfacial forces dominate the structure of smaller particles, resulting in size-dependent compact isomers that have ring and pore distributions different from open framework zeolites. The instability of zeolites smaller than $4 \mathrm{~nm}$ precludes a classical mechanism of nucleation from solution or through assembly of small nanoslabs.
\end{abstract}

Nanozeolites with sizes 20 to $150 \mathrm{~nm}$ are gaining significant attention because of their superior performance as catalysts and adsorbents, ${ }^{[1-3]}[2,4]$ and their use in membranes..$^{[5]}$ In the quest of enhancing the catalytic performance of these microporous materials, there has been an increased interest in synthesizing zeolite nanoparticles containing just a few unit cells. Tsapatsis and coworkers recently produced a range of few unit-cell MFI zeolites with diameters below $10 \mathrm{~nm}$, imaging crystallites as small as $\sim 6 \mathrm{~nm}$, and deducing from $\mathrm{x}$-ray broadening that some were as small as $4 \mathrm{~nm} \cdot{ }^{[6]}$ To date, it is not known what is the smallest zeolite that could be produced by hydrothermal synthesis.

The hydrothermal synthesis of zeolites is mediated by the formation of amorphous precursor nanoparticles wherein the crystals are born. ${ }^{[7-11]}$ The high ratio of area to volume in nanoparticles results in higher solubilities of nanoscopic zeolites compared to their bulk counterparts ${ }^{[12-13]}$ and a decrease in the temperature of crystal to amorphous melting transition. The latter is evident in the comparison of the $\sim 1100^{\circ} \mathrm{C}$ at which bulk silicalite-1 loses crystallinity ${ }^{[14]}$ to the $\sim 750{ }^{\circ} \mathrm{C}$ at which that occurs for its $\sim 7 \mathrm{~nm}$ crystallites. ${ }^{[6]}$ What is the particle size at which the zeolite would be less stable than the amorphous precursor at the 60 to $180^{\circ} \mathrm{C}$ temperatures typical of hydrothermal synthesis? While zeolites are open frameworks, oligomers at the early stage of zeolite synthesis are rather compact. ${ }^{[15-16]}$ What is the smallest particle size for which an open silica framework is more stable than compact isomers? In this communication, we address these questions using thermodynamic analysis and molecular simulations.

The crystal to amorphous equilibrium temperature of nanoparticles of diameter $D, T_{\mathrm{m}}(D)$, is related to the bulk melting temperature, $T_{m}^{\text {bulk }}$ through the Gibbs-Thomson (GT) equation, ${ }^{[17-18]}$

$$
T_{\mathrm{m}}(D)=T_{\mathrm{m}}^{\text {bulk }}-2 K_{\mathrm{GT}} /(D-2 \delta)
$$

where $\delta$ is the width of the disordered layer around the zeolite nanocrystal, and $K_{\mathrm{GT}}=3 T_{\mathrm{m}}^{\text {bulk }} \gamma_{\mathrm{sl}} v_{\mathrm{s}}^{-1 / 3} / \Delta H_{\mathrm{m}}$, with $\gamma_{\mathrm{sl}}$ the solidliquid surface tension, $v_{s}$ the molar volume of the solid, and $\Delta H_{\mathrm{m}}$ the molar enthalpy of melting. The main limitation in calculating $T_{\mathrm{m}}(D)$ is the lack of zeolite-amorphous surface tension data. We bridge this gap using Turnbull's relation between surface tension and enthalpy of melting, $\gamma_{\mathrm{sl}}=$ $\lambda \Delta H_{\mathrm{m}} v_{\mathrm{s}}^{-2 / 3}$, which leads to $K_{\mathrm{GT}}=3 \lambda T_{\mathrm{m}}^{\text {bulk }} v^{1 / 3}$, where $\lambda$ is a constant experimentally determined to be between 0.32 to 0.49 for a wide variety of crystals. ${ }^{[19]}$ Below we show that molecular simulations for a model zeolite predict $T_{\mathrm{m}}(D)$ in excellent agreement with Eq. 1 with $\lambda=0.40$ and $\delta=0.28 \mathrm{~nm}$. The latter is narrower than the typical $\sim 0.32 \mathrm{~nm}$ Si-Si distance in zeolites, indicating very little disorder at the zeolite-solution interface.

Assuming that $\lambda$ and $\delta$ are common to all zeolites, $T_{\mathrm{m}}(D)$ for any zeolites can be computed from their bulk melting temperature, $T_{m}^{\text {bulk }}$. Here we use the collapse temperature of zeolites, $T_{\text {collapse, }}$ as a proxy for their melting temperatures. Silicalite-1 is one of the most stable zeolites, as gleaned from its high $T_{\text {collapse }} \approx 1100$ ${ }^{\circ} \mathrm{C} \cdot{ }^{[14,20]}$ The $1100{ }^{\circ} \mathrm{C}$ at which silicalite- 1 loses crystallinity is consistent with the $837-1561{ }^{\circ} \mathrm{C} T_{\mathrm{m}}^{\text {bulk }}$ predicted from experimental thermodynamic data (Supp. Section A.1). Fig. 1a presents the zeolite-amorphous equilibrium temperature as a function of nanoparticle diameter predicted with Eq. 1 for three common zeolites: silicalite- $1\left(\mathrm{MFI}, T_{\mathrm{m}}^{\text {bulk }}=1100 \pm 300{ }^{\circ} \mathrm{C}\right)$, faujasite $\left(\mathrm{FAU}, T_{\mathrm{m}}^{\text {bulk }}=800{ }^{\circ} \mathrm{C}^{[21]}\right)$ and beta $\left(\mathrm{BEA}, T_{\mathrm{m}}^{\text {bulk }}=760\right.$ ${ }^{\circ} \mathrm{C}^{[22]}$ ). We find that $T_{\mathrm{m}}(D)$ of these zeolites decreases slowly as the particle size diminishes to about $\sim 20 \mathrm{~nm}$, consistent with the experimental finding that the framework energy of zeolites larger than $40 \mathrm{~nm}$ is essentially the same as in the bulk crystal. ${ }^{[23]}$ As $D$ decreases from $\sim 20$ and $\sim 5 \mathrm{~nm}$, the GT equation predicts that the stability decreases slowly, capturing well the experimental melting of $\sim 7 \mathrm{~nm}$ silicalite-1 particles ${ }^{[6]}$ (blue star in Fig 1a).

Fig 1a reveals that $T_{\mathrm{m}}(D)$ decreases quite sharply for $D<5 \mathrm{~nm}$, plunging below the synthesis temperature when the diameter is about $2 \mathrm{~nm}$, a typical size of zeolite unit cell. A $2 \mathrm{~nm}$ diameter silicalite-1 particle contains just one 10-membered ring pore surrounded by 5 - and 6 -membered rings (Fig $1 \mathrm{~b}$, panel i), with a total of $86 \mathrm{SiO}_{2}$ units $\left(N_{\mathrm{SiO}_{2}}\right)$, comparable to the 96 in its unit cell. ${ }^{24]} 29$ The crossover of $T_{\mathrm{m}}(D)$ and the temperature of synthesis indicates that single-unit-cell zeolites would be, at best, barely stable at synthesis conditions. Moreover, Fig 1a predicts that, if synthesized, these unit-cell zeolites would melt and sinter into larger particles before the SDA could be eliminated by calcination at $\sim 550^{\circ} \mathrm{C}$. 
(b)

$$
D=2 \mathrm{~nm} \quad D=3 \mathrm{~nm} \quad D=4 \mathrm{~nm} \quad D=5 \mathrm{~nm}
$$

(a)

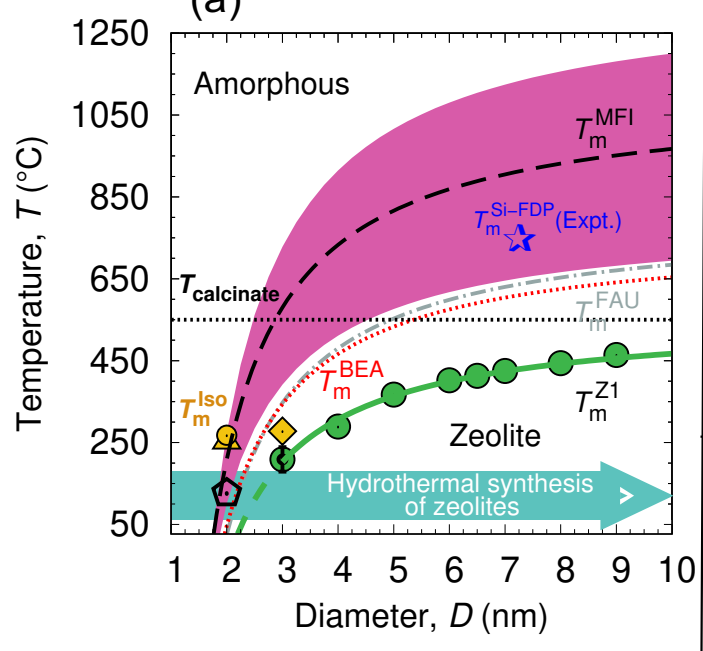

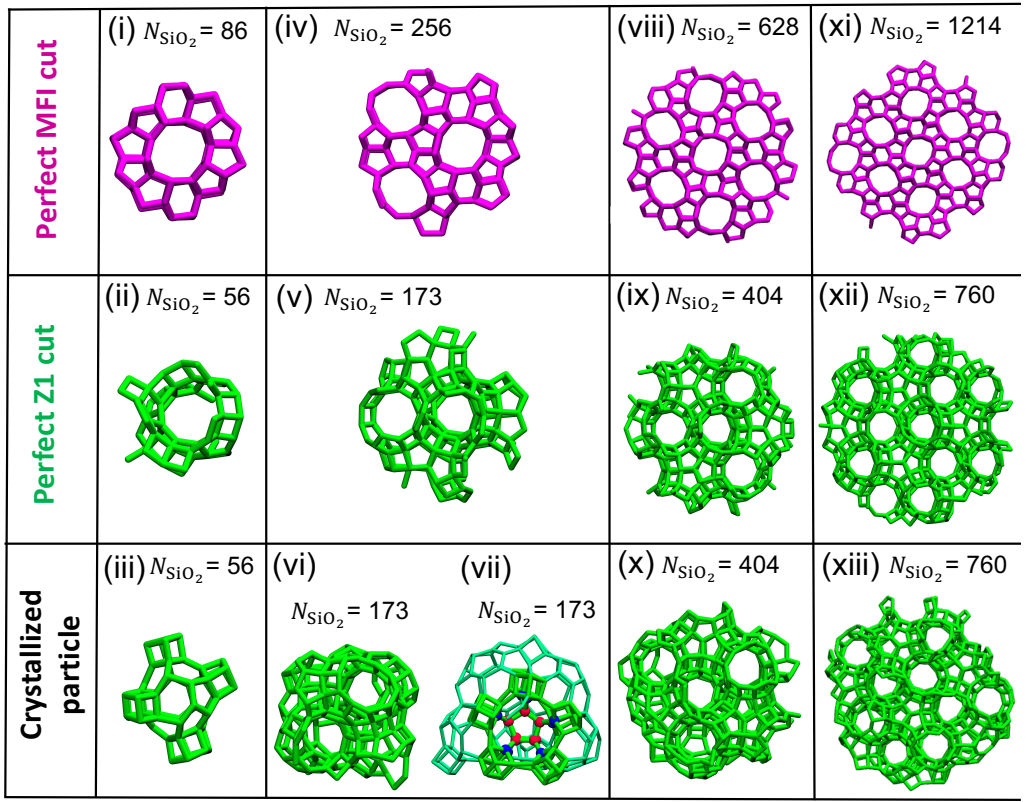

Figure 1. Size-dependent stability and structure of zeolites. a) Particle size affects the crystal-to-amorphous transition temperature, $T_{\mathrm{m}}(D)$ of nano-zeolites. Black dashed line shows $T_{\mathrm{m}}(D)$ of silicalite-1 as a function of particle diameter computed with the GT-equation; the magenta-shaded region shows the range with error bar; the blue star is the experimental collapse temperature of a $\sim 7 \mathrm{~nm}$ all-silica zeolite in ref. [6]. Red dotted and grey dotted-dashed lines are the $T_{\mathrm{m}}(D)$ predicted with eq. 1 for BEA and FAU zeolites, respectively. The green circles are amorphization temperatures calculated for Z1 nanozeolites through molecular simulations; and the green line is their fit with the GT equation. The empty black pentagon indicates the temperature of zeolite to compact isomer for 2 nm silicalite-1 and Z1. Yellow symbols indicate the compact ordered isomer to amorphous transition in simulations of particles with $(\mathrm{SiO} 2)_{n}$ units with $\mathrm{n}=56$ (yellow circle), 86 (yellow triangle) and 173 (yellow diamond) in a solution with SDA. The cyan arrow illustrates a range of pathways of zeolite synthesis, for which partiicle size grows at constant temperature. (b) Structure of nanozeolites and competing compact isomers. Top middle panel present spherical cuts of MFI and Z1 that maximize the degree of condensation. The bottom panel presents the structure of the nanoparticles crystallized in simulations in aqeuous solution with SDA. $N_{\text {SiO2 }}$ indicates the number of $\mathrm{SiO}_{2}$ units in each structure.

The Gibbs-Thomson equation assumes that the zeolite is the ordered structure: it cannot predict the particle size at which the crystal phase ends, ${ }^{[25]}$ giving rise to a prevalence of more compact size-dependent isomers. We elucidate this limit using molecular dynamics simulations with the TS+W model, ${ }^{[26]}$ which is first to represent all stages of hydrothermal synthesis. ${ }^{[26]}$ The model reproduces the experimental structure of silica oligomers in the early stages of synthesis, the $Q^{n}$ speciation of silica as it polymerizes into nanoscopic amorphous precursors, and their crystallization into a zeolite. ${ }^{[26]}$

The current parameterization of SDA in TS+W stabilizes zeolite $Z 1,{ }^{[26]}$ which has the structure of FIR-30 metal organic framework. ${ }^{[27-29]} \mathrm{Z} 1$ has 10 -member ring channels, ${ }^{[29]}$ same as silicalite-1, ${ }^{[24]}$ with a framework density about $30 \%$ lower, comparable to the one of faujasite. Z1 has about $15 \%$ undercoordinated silica sites ${ }^{[27]}$ that render it $5.14 \mathrm{~kJ} / \mathrm{mol}$ less stable than silicalite- 1 , and a relatively low $T_{\mathrm{m}}^{\text {bulk }}=560^{\circ} \mathrm{C} .^{[30]}$ For reference, the model predicts that silicalite- 1 is $1.21 \mathrm{~kJ} / \mathrm{mol}$ more stable than BEA, close to the $2.5 \pm 1.15 \mathrm{~kJ} / \mathrm{mol}$ obtained by calorimetry. ${ }^{[31]}$ We use molecular simulations to compute the zeolite to amorphous equilibrium temperature of Z1 nanoparticles (some of them shown in the middle row of Fig $1 \mathrm{~b}$ ) immersed in aqueous solution of SDA. Fig 1 shows that $T_{\mathrm{m}}(D)$ follows Eq. 1 down to zeolites as small as $3 \mathrm{~nm}$, which contain just 2 pores and $35 \%$ more silica units than in a single unit cell. We conclude that the Gibbs-Thomson relation holds for zeolites of dimensions comparable to a single unit cell.
To assess the relative stability of small zeolites and competing structures, we investigate the nucleation of $Z 1$ zeolite in cooling simulations of amorphous nanoparticles with diameter 9 to $2 \mathrm{~nm}$ (Supp. Section A.2). The ratio of silica to SDA in the aqueous synthesis mixture is $3 \pm 0.3$, same as used in the synthesis of silicalite-1. ${ }^{[32]}$ Fig $1 \mathrm{~b}$ shows snapshots of perfect Z1 nanoparticles of various sizes (mid row), as well as the structures obtained after their melting and recrystallization in cooling simulations (bottom row). We find that the zeolite can be consistently nucleated and grown in precursors as small as $4 \mathrm{~nm}$, the lower size range detected in the experiments. ${ }^{\left[{ }^{6]}\right.}$

The ordered structure formed by cooling $3 \mathrm{~nm}$ amorphous precursors depends on the ratio of silica to SDA in the synthesis mixture. A precursor with silica to SDA ratio 3.0 produces a distinct compact isomer (panel vii in Fig $1 b$ ) that does not share the ring or pore distribution of zeolite Z1 of the same size (Fig 2 $a-b)$. However, we find that doubling the concentration of SDA (silica to SDA ratio 1.5) reinforces the formation of the 10member ring pores, crystallizing a $3 \mathrm{~nm}$ zeolite (panel vi in Fig 1b). Nevertheless, the $3 \mathrm{~nm}$ zeolite is less stable than the compact isomer with same number of $\mathrm{SiO}_{2}$ units, as evidenced by its lower melting temperature, 209 versus $271^{\circ} \mathrm{C}$ (Fig 1a). We conclude that the zeolite phase ends for particles with diameter $\sim 3 \mathrm{~nm}$.

Amorphous precursors smaller than $3 \mathrm{~nm}$ order into more stable size-specific ordered isomers. It is not possible to nucleate a zeolite from $2 \mathrm{~nm}$ precursors, irrespective of the silica to SDA ratio. Perfect $2 \mathrm{~nm}$ crystallites of $Z 1$ spontaneously transform to 
an ordered, more compact isomer with energy $8 \%$ lower than the $2 \mathrm{~nm}$ zeolite upon heating (Fig S5). The same compact isomer - with pores and rings smaller than those in the zeolite (Fig 2c-d) - is obtained by crystallization of the $2 \mathrm{~nm}$ amorphous precursor (Fig 1b). Likewise, we find that a $2 \mathrm{~nm}$ silicalite-1, one of the most stable zeolites, ${ }^{[31]}$ spontaneously rearranges into an ordered compact isomer at $\sim 112^{\circ} \mathrm{C}$ (Fig 3 ). That ordered isomer is stable up to $268{ }^{\circ} \mathrm{C}$, further supporting that compact silica structures are more stable than single pore, unit cell zeolites.
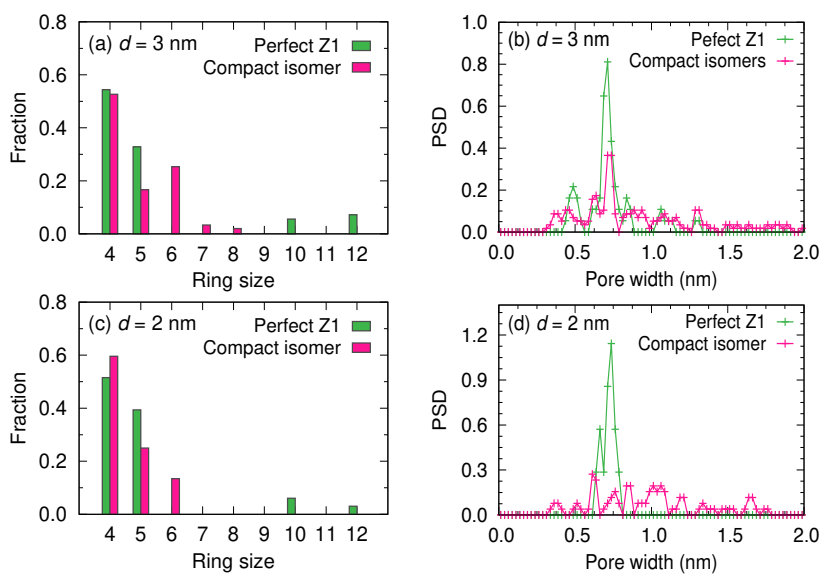

Figure 2. Structural analysis of the species formed at very small sizes. (a \& c) ring size distribution and (c \& d) pore size distribution for $3 \mathrm{~nm}$ (upper panels) and $2 \mathrm{~nm}$ (lower panels) particles.

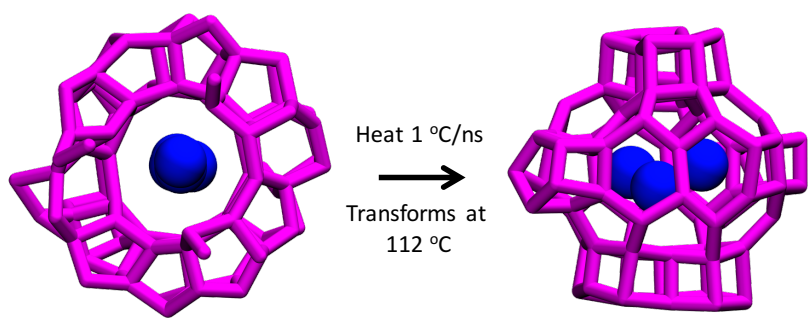

Figure 3. A $2 \mathrm{~nm}$ single pore silicalite-1 nanoparticle in aqueous solution of SDA spontaneously rearranges into a more stable compact isomer at temperatures of hydrothermal synthesis.

As silica favors four-coordinated structures, the degree of condensation - an average of the population $Q^{n}$ of silica with $n$ silica neighbors $c=1 /{ }_{4} \sum_{n=0}^{4} \mathrm{n} Q^{\mathrm{n}[33]}-$ can be used as a proxy for the stability of the framework. The under-coordination of silica at the surface of nanoparticles leads to a decrease in $c$ with size (Fig 4), retracing the decrease in $T_{\mathrm{m}}(D)$ in Fig $1 \mathrm{a}$. The degree of condensation of silicalite-1 nanoslabs proposed to be intermediates in the synthesis of silicalite- $1^{[34]}$ is never higher than for spherical silicaliite-1 particles with same number of $\mathrm{SiO}_{2}$ units (Fig 4 and Supp. Fig S2), indicating that nanoslabs would also be outcompeted by more stable compact isomers.

Indeed, the compact isomers obtained for $3\left(N_{\mathrm{SiO}_{2}}=173\right)$, and 2 $\mathrm{nm}\left(N_{\mathrm{SiO}_{2}}=56\right)$ particles have significantly higher degree of condensation than the corresponding perfect $\mathrm{Z} 1$, and even larger than same-sized perfect silicalite-1 particles (Fig 4). We conclude that the interfacial forces that eliminate undercoordinated $Q^{1}$ and $Q^{2}$ silica-species in these small particles (Sup. Fig. S6) lead to the complete reorganization of the structure of crystallites smaller than $4 \mathrm{~nm}$, setting the limit of stability of open zeolite frameworks.

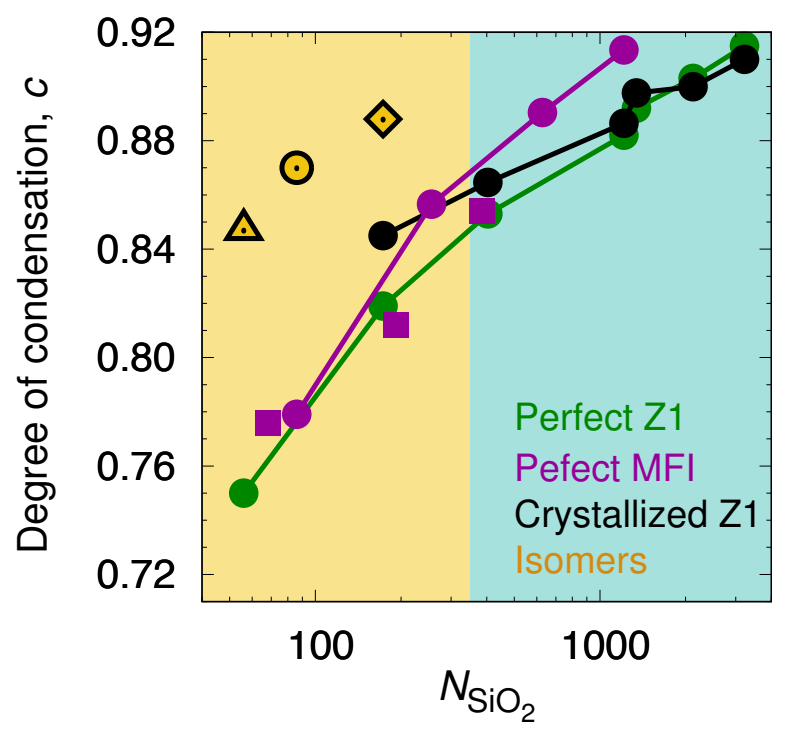

Figure 4. Degree of condensation $c$ of ordered structures as the size of the particles, measured in their number of $\mathrm{SiO}_{2}$ units. Magenta circles show $c$ of perfectly cut zeolite silicalite-1 MFI, magenta squares show perfect rectangular nanoslabs (structures in Supp. Fig. S2), green circles of perfect Z1 and black circles for Z1 crystallized from solution. Yellow symbols present $c$ values of stable compact isomers obtained by recrystallization of small precursors in the zeolite synthesis mixture. The degree of condensation of Z1 zeolites crystallized from the 3 and $4 \mathrm{~nm}$ spherical amorphous particles is higher than of their perfect counterparts, due to reorganization of their interface to decrease $Q^{1}$ and $Q^{2}$ (Supp. Fig S6).

The compact isomers that outcompete the smallest zeolites are rich in D4R and D5R subunits, which abound in the early stages of polymerization, ${ }^{[15]}$ but are absent in the bulk crystals of silicalite- ${ }^{[35]}$ and Z1. ${ }^{[27,29]}$ The pathway of hydrothermal synthesis of zeolites involves growth of particles at controlled temperature (cyan arrow in Fig 1a). Along that path, zeolite crystals of any shape are less stable than amorphous precursors or compact ordered isomers for particles smaller than $4 \mathrm{~nm}$ (Fig 4). The instability of zeolites smaller than $3 \mathrm{~nm}$ rules out the possibility of classical crystallization from solution or through assembly of zeolite nanoslabs. ${ }^{[36]}$

In summary, the thermodynamic analysis and molecular simulations presented here predict that zeolites smaller than 4 $\mathrm{nm}$ cannot be obtained through hydrothermal synthesis. We find that interfacial forces dominate below that size, destabilizing the framework to produce size-specific ordered more compact isomers with distributions of rings, pores, degree of condensation, and x-ray spectra (Fig. S8) different from those of zeolites. We do not expect these compact isomers to have the adsorption selectivity or catalytic activity for which zeolites are prized. As the collapse temperature of most zeolites fall within the range of those studied here, ${ }^{[20]}$ our conclusions apply to the synthesis of a broad category of ultra-small zeolites.

\section{Acknowledgements}

The work is funded by US Department of Energy through BES award DE-SC0020201. The authors thank the Center for HighPerformance Computing at the University of Utah for technical support and an award of computing time. 
Keywords: Zeolites $\cdot$ Hydrothermal synthesis $•$ Microporous

materials $\cdot$ Phase transitions $\cdot$ Thermodynamics

[1] E. Kianfar, Journal of Sol-Gel Science and Technology 2019, 91, 415-429.

[2] L. Tosheva, V. P. Valtchev, Chemistry of Materials 2005, 17, 2494-2513.

[3] L. Burel, A. Tuel, Microporous and Mesoporous Materials 2013, 174, 90-99.

[4] S. C. Larsen, The Journal of Physical Chemistry C 2007, $111,18464-18474$.

[5] M. Zaarour, B. Dong, I. Naydenova, R. Retoux, S. Mintova Microporous and Mesoporous Materials 2014, 189, 11-21.

[6] P. Lu, S. Ghosh, M. Dorneles de Mello, H. S. Kamaluddin X. Li, G. Kumar, X. Duan, M. Abeykoon, J. A. Boscoboinik, L. Qi, et al., Angewandte Chemie International Edition 2021, 60, 19214

[7] C. S. Cundy, P. A. Cox, Microporous and Mesoporous Materials 2005, 82, 1-78.

[8] J. D. Rimer, D. G. Vlachos, R. F. Lobo, The Journal of Physical Chemistry B 2005, 109, 12762-12771.

[9] T. M. Davis, T. O. Drews, H. Ramanan, C. He, J. Dong, H. Schnablegger, M. A. Katsoulakis, E. Kokkoli, A. V. McCormick, R. L. Penn, M. Tsapatsis, Nature Materials 2006, 5, 400-408

[10] S. Kumar, Z. Wang, R. L. Penn, M. Tsapatsis, Journal of the American Chemical Society 2008, 130, 17284-17286.

[11] Z. Sheng, H. Li, K. Du, L. Gao, J. Ju, Y. Zhang, Y. Tang, Angewandte Chemie International Edition 2021, 60, 13444-13451.

[12] P. Vinaches, K. Bernardo-Gusmão, S. B. C. Pergher, Molecules 2017, 22

[13] G. Madras, B. J. McCoy, Chemical Engineering Science 2004, 59, 2753-2765

[14] S. P. Zhdanov, N. N. Feoktistova, N. I. Kozlova, M. M. Piryutko, Bulletin of the Academy of Sciences of the USSR, Division of chemical science 1985, 34, 2467-2472.

[15] C. T. G. Knight, S. D. Kinrade, The Journal of Physical Chemistry B 2002, 106, 3329-3332.

[16] M. Ciantar, T. T. Trinh, C. Michel, P. Sautet, C. MellotDraznieks, C. Nieto-Draghi, Angewandte Chemie International Edition 2021, 60, 7111-7116.

[17] H. K. Christenson, Journal of Physics: Condensed Matter 2001, 13, R95-R133.

[18] O. V. Petrov, I. Furó, Progress in Nuclear Magnetic Resonance Spectroscopy 2009, 54, 97-122.

[19] D. Turnbull, Journal of Applied Physics 1950, 21, 1022 1028.

[20] G. Cruciani, Journal of Physics and Chemistry of Solids 2006, 67, 1973-1994.

[21] P. R. d. S. de Castroa, A. Á. B. M. Maiaa, R. S. Angelicab, Materials Research 2019, 22, e20190321.

[22] S.-b. Liu, J.-F. Wu, L.-J. Ma, T.-C. Tsai, I. Wang, Journal of Catalysis 1991, 132, 432-439.

[23] Q. Li, S. Yang, A. Navrotsky, Microporous and Mesoporous Materials 2003, 65, 137-143.

[24] E. M. Flanigen, J. Bennett, R. Grose, J. Cohen, R. Patton, R. Kirchner, J. Smith, Nature 1978, 271, 512-516.

[25] D. R. Moberg, D. Becker, C. W. Dierking, F. Zurheide, B. Bandow, U. Buck, A. Hudait, V. Molinero, F. Paesani, T. Zeuch, Proceedings of the National Academy of Sciences 2019, 116, 24413

[26] D. Dhabal, A. A. Bertolazzo, V. Molinero, J. Phys. Chem. C 2021, (Under Review).

[27] A. Kumar, M. Zare, V. Molinero, The Journal of Physical Chemistry C 2019, 123, 971-978.

[28] A. Kumar, V. Molinero, The Journal of Physical Chemistry Letters 2018, 9, 5692-5697.

[29] A. Kumar, A. H. Nguyen, R. Okumu, T. D. Shepherd, V. Molinero, Journal of the American Chemical Society 2018 140, 16071-16086.

[30] D. Dhabal, A. A. Bertolazzo, V. Molinero, The Journal of Physical Chemistry C 2021, 125, 26857-26868.

[31] A. Navrotsky, O. Trofymluk, A. A. Levchenko, Chemical Reviews 2009, 109, 3885-3902.
[32] J. D. Rimer, J. M. Fedeyko, D. G. Vlachos, R. F. Lobo Chemistry - A European Journal 2006, 12, 2926-2934.

[33] F. Devreux, J. P. Boilot, F. Chaput, A. Lecomte, Physical Review A 1990, 41, 6901-6909.

[34] C. E. Kirschhock, V. Buschmann, S. Kremer, R. Ravishankar, C. J. Houssin, B. L. Mojet, R. A. van Santen, P. J. Grobet, P. A. Jacobs, J. A. Martens, Angew. Chem. Int. Ed. 2001, 40, 2637-2640.

[35] D. P. Petry, M. Haouas, S. C. C. Wong, A. Aerts, C. E. A. Kirschhock, J. A. Martens, S. J. Gaskell, M. W. Anderson, F. Taulelle, The Journal of Physical Chemistry C 2009, 113, 20827-20836.

[36] R. Ravishankar, C. E. A. Kirschhock, P.-P. Knops-Gerrits, E. J. P. Feijen, P. J. Grobet, P. Vanoppen, F. C. De Schryver, G. Miehe, H. Fuess, B. J. Schoeman, P. A. Jacobs, J. A. Martens, The Journal of Physical Chemistry B 1999, 103, 4960-4964

\section{Entry for the Table of Contents}

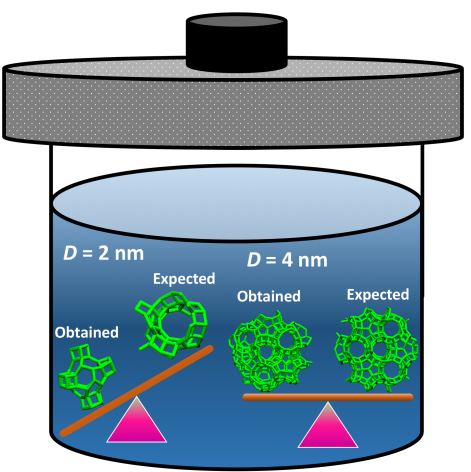

Thermodynamic analysis and molecular simulations indicate that zeolites as small as $4 \mathrm{~nm}$ can be obtained by hydrothermal synthesis. Compact size-dependent isomers outcompete zeolites at smaller sizes. 


\title{
SUPPLEMENTARY INFORMATION FOR
}

\section{What is the Smallest Zeolite that could be Synthesized?}

\author{
Debdas Dhabal, ${ }^{a}$ Andressa A. Bertolazzo ${ }^{a}$ and Valeria Molinero ${ }^{\mathrm{a}, *}$ \\ ${ }^{a}$ Department of Chemistry, The University of Utah, Salt Lake City, UT-84112-0850, USA.
}

\section{A. Methods}

\section{A.1. Estimation of Melting Temperature of Silicalite-1 from Available Thermodynamic Data}

The bulk melting temperature of zeoliites can be obtained from the ratio of their enthalpy and entropy of melting, $T_{\mathrm{m}}=\Delta H_{\mathrm{m}} / \Delta S_{\mathrm{m}}$. However, the enthalpy and entropy or melting of silicalite- 1 are not yet available in the literature. We estimate these properties from available thermodynamic data of stable silica polymorphs (quartz, cristobalite) and the difference in enthalpy between silicalite-1 and quartz. ${ }^{1-2}$ In what follows we present a brief description of how we compute the $T_{\mathrm{m}}^{\mathrm{bulk}}$ using two approximations.

i) Considering cristobalite as a reference, we write the enthalpy of melting of silicalite-1 (zeolite MFI) as:

$$
\Delta H_{\mathrm{m}}^{\mathrm{MFI}}=\Delta H_{\mathrm{m}}^{\text {Cristobalite }}-\Delta H_{\mathrm{ex}}^{\mathrm{MFI} \rightarrow \text { Cristobalite }}
$$

The enthalpy of fusion for cristobalite at $1999 \mathrm{~K}^{\text {is }} 8.9 \mathrm{~kJ} \mathrm{~mol}^{-1} .{ }^{3} \Delta H_{\mathrm{ex}}^{\mathrm{MFI} \rightarrow \text { Cristobalie }}$ can be obtained from their individual enthalpy of transition of MFI zeolite and cristobalite with respect to the quartz at $298 \mathrm{~K}$ :

$$
\begin{aligned}
\Delta H_{\mathrm{ex}}^{\mathrm{MFI} \rightarrow \text { Cristobalite }} & =\Delta H_{\text {trans }}^{\text {Quartz } \rightarrow \mathrm{MFI}}-\Delta H_{\text {trans }}^{\text {Quartz } \rightarrow \text { Cristobalite }} \\
& \approx(6.8-2.84) \mathrm{kJ} \mathrm{mol}^{-1} \\
& \approx 3.96 \mathrm{~kJ} \mathrm{~mol}^{-1}
\end{aligned}
$$

If we neglect the effect of temperature on the enthalpies, then $\Delta H_{\mathrm{m}}^{\mathrm{MFI}}=(8.9-3.96) \mathrm{kJ} \mathrm{mol}^{-1}=4.94 \mathrm{~kJ}$ $\mathrm{mol}^{-1}$. If we further approximate that the entropy of melting of MFI zeolite is the same as for cristobalite, then:

$$
\begin{gathered}
\Delta S_{\mathrm{m}}^{\mathrm{MFI}} \approx \Delta S_{\mathrm{m}}^{\text {Cryistobalite }} \approx \frac{8900}{1999} \\
\approx 4.45 \mathrm{~J} \mathrm{~mol}^{-1} \mathrm{~K}^{-1}
\end{gathered}
$$

we can now calculate the melting temperature as $T_{\mathrm{m}}^{\mathrm{MFI}} \approx 4940 / 4.45 \approx 1110 \mathrm{~K}=837^{\circ} \mathrm{C}$. This value is lower than the one estimated considering the collapse temperature of silicalite-1 ( 1100 ${ }^{\circ} \mathrm{C}^{4}$ ) as a proxy for its melting temperature.

ii) Ref. ${ }^{5}$ reports both the enthalpy and entropy of transition of silicalite- 1 and silica glass with respect to quartz at $1000 \mathrm{~K}$. Using those values, we calculate the transition enthalpy $\left(\Delta H_{\mathrm{m}}^{\text {Glass-Silicalite }}=3.76 \mathrm{~kJ} \mathrm{~mol}^{-1}\right)$ and entropy $\left(\Delta S_{\mathrm{m}}^{\mathrm{Glass}-\text { Silicalite }}=2.05 \mathrm{~J} \mathrm{~K}^{-1} \mathrm{~mol}^{-1}\right)$ of silicalite- 1 with respect to the glass. As the transition temperature is $1000 \mathrm{~K}$, close to the melting temperature of silicalite- 1 discussed above, we use these values to estimate $T_{\mathrm{m}}$, which we find to be $\approx 1834 \mathrm{~K}=1561^{\circ} \mathrm{C}$. 
Our results are listed in Table S1. All energies and entropies are present as per mole of $\mathrm{SiO}_{2}$ unit.

Table S1. Estimated values of enthalpy and entropy of melting along with the melting temperature of silicalite-1 (MFI) from available thermodynamic data. Case (i) considers the entropy of fusion of the zeolite framework $\left(\Delta S_{\mathrm{m}}\right)$ as approximately the same as cristobalite $\left(\Delta S_{\mathrm{m}}^{\text {Zeolite }} \approx \Delta S_{\mathrm{m}}^{\text {Cristobalite }}\right)^{2}$ and the enthalpy of fusion of the framework $\left(\Delta H_{\mathrm{m}}\right)$ is calculated using the cristobalite enthalpy of fusion, ${ }^{3}$ with the excess enthalpy from between cristobalite and MFI at $298 \mathrm{~K}^{1}$ Case (ii) considers the excess enthalpy and entropy of silicalite- 1 and glass relative to quartz at $1000 \mathrm{~K}$ from ref. ${ }^{5}$

\begin{tabular}{|c|c|c|c|}
\hline Case & $\Delta H_{\mathrm{m}}\left(\mathrm{kJ} \mathrm{mol}^{-1}\right)$ & $\Delta S_{\mathrm{m}}\left(\mathrm{J} \mathrm{mol}^{-1} \mathrm{~K}^{-1}\right)$ & $T_{\mathrm{m}}\left({ }^{\circ} \mathrm{C}\right)$ \\
\hline (i) & 4.94 & 4.45 & 837 \\
\hline (iii) & 3.76 & 2.05 & 1561 \\
\hline
\end{tabular}

\section{A.2. Molecular Dynamics Simulations}

We perform the molecular simulations using the recently developed TS+W model, ${ }^{6}$ which is based on short-ranged anisotropic potentials and a coarse-grained representation. The model has 3 components: monatomic silica $(\mathrm{T})$, structure directing agent $(\mathrm{S})$ and water $(\mathrm{W})$ as a solvent. We model $\mathrm{W}$ with the monatomic $\mathrm{mW}$ model ${ }^{7}$ which represents interactions between water molecules through a Stillinger-Weber (SW) potential. ${ }^{8}$ Interactions between the monatomic silica T are modeled with a twobody SW form, whereas the cosine quadratic component of the three-body part of the SW potential is replaced with a function that favors T-T-T angles found in silica zeolites. ${ }^{6}$ The structure directing agent $S$ interact with other $S, T$ and $\mathrm{W}$ only through two-body SW form interactions. The model represents the W-T and W-S interactions with two-body SW potentials with interaction strength $\varepsilon=0.75 \mathrm{kcal} \mathrm{mol}$ ${ }^{1}$, all other parameters of the TS+W model are provided in ref ${ }^{6}$. It has been shown that TS+W model is able to reproduce the crucial steps of hydrothermal synthesis, polymerization, crystallization and dehydration of water from the zeolite at higher temperature. ${ }^{6}$

All molecular dynamics simulations presented in this study are performed in LAMMPS simulation package. ${ }^{9}$ The equation of motions are integrated using the velocity Verlet algorithm with a time step of 5 fs. Periodic boundary conditions are applied in the three Cartesian directions in all simulations. The simulations are performed in the $N p T$ ensemble at 1 bar, controlling the temperature and pressure through the Nose-Hoover thermostat and barostat, respectively. The time constant of the thermostat and barostat are 5 ps and 25 ps, respectively. The simulation snapshots presented in the manuscript are prepared using Visual Molecular Dynamics software VMD. ${ }^{10}$

To calculate the melting temperature of individual zeolite $\mathrm{Z} 1$ particles of diameters $\mathrm{D}=5,6,7,8$ and $9 \mathrm{~nm}$, we first prepare the zeolite particles by performing cooling simulations from an amorphous particle of same sizes containing the number of silica and SDA and water molecules mentioned in Table S2. To prepare the amorphous particles in solution, we take a well equilibrated rectangular simulation cell of approximate dimensions of $9 \times 27 \times 10.5 \mathrm{~nm}^{3}$ containing $10969 \mathrm{~T}, 3848 \mathrm{~S}$ and $42903 \mathrm{~W}$ particles. This cell contains a hydrated SDA-silica dense amorphous slab of approximate dimensions of $9 \times 10 \times$ $10.5 \mathrm{~nm}$ sandwiched by two $\sim 8.5 \mathrm{~nm}$ wide water-rich solution slabs in $y$-direction. Using LAMMPS's 
"region" command we select a spherical region of the desired size in the center of the amorphous slab and convert all $\mathrm{T}$ and $\mathrm{S}$ outside that region into $\mathrm{W}$ particles. Then, we change the box shape (using "change_box" command in LAMMPS) to cubic, keeping the number of particles in the simulation cell. The cubic simulation box with the spherical silica-rich amorphous precursor phase immersed in water is then energy minimized and equilibrated at $417{ }^{\circ} \mathrm{C}$ with isotropic pressure coupling in the three Cartesian directions. The constituent species can freely exchange between water-rich and silica-rich phases. The water mole fraction in the amorphous phase is approximately 0.53 at $417{ }^{\circ} \mathrm{C}$. Starting from this configuration we then perform cooling simulations with a specified rate for different particle sizes mentioned in the Table S2, until a well-defined Z1 crystal appears. The zeolite particles of different sizes are then heated with a linear temperature ramp with rate $1{ }^{\circ} \mathrm{C} / \mathrm{ns}$ (Table S2) to estimate the corresponding melting temperature. For the particle of diameter $D=6.5 \mathrm{~nm}$, the amorphous aggregate after polymerization of a homogeneous mixture with $N_{\mathrm{W}}=48507, N_{\mathrm{T}}=1889$, and $N_{\mathrm{S}}=664$ at a temperature of $407^{\circ} \mathrm{C}$ is used as a starting point for the cooling simulation (rate mentioned in Table S2) to crystallize a nanozeolite. This is then heated with a ramp at $1{ }^{\circ} \mathrm{C} / \mathrm{ns}$ to get the melting temperature.

As it is difficult to crystalize a perfect zeolite $\mathrm{Zl}$ of small sizes, the melting temperature for the particle diameter $D=2,3$ and $4 \mathrm{~nm}$ are performed starting from a perfectly cut $Z 1$ from a large slab. We take a large SDA-filled zeolite slab $\left(x_{\mathrm{T}}=0.74\right.$ between $\mathrm{T}$ and $\left.\mathrm{S}\right)$ previously grown in Ref ${ }^{6}$ and cut spherical particles with diameter $D=2,3$ and 4 nm using LAMMP's "region" command. We remove the rest of the particles in the simulation box and solvate these zeolites with the number of water molecules indicated in Table S2. The simulation box is then energy minimized and equilibrated for $10 \mathrm{~ns}$ at $27^{\circ} \mathrm{C}$. These particles of different sizes are then heated in a linear ramp at $1{ }^{\circ} \mathrm{C} / \mathrm{ns}$ (Table S2) for the calculation of their $T_{\mathrm{m}}$.

Table S2. Heating and cooling rates used to amorphize and crystallize zeolite Z1. Number of T, S and W particles present in the simulation boxes for zeolite particles of different diameters.

\begin{tabular}{|c|c|c|c|c|c|}
\hline$D(\mathbf{n m})$ & $\mathbf{N}_{\mathrm{T}}$ & $\mathbf{N}_{\mathrm{s}}$ & $N_{\mathbf{w}}$ & $\begin{array}{l}\text { Heating rate } \\
\qquad\left({ }^{\circ} \mathrm{C} \mathbf{n s}^{-1}\right)\end{array}$ & $\begin{array}{c}\text { Cooling rate } \\
\left({ }^{\circ} \mathbf{C} \mathbf{n s}^{-1}\right)\end{array}$ \\
\hline 9.0 & 4608 & 1404 & 51708 & 1.0 & 1.0 \\
\hline 8.0 & 3221 & 960 & 53539 & 1.0 & 1.0 \\
\hline 7.0 & 2125 & 658 & 54937 & 1.0 & 1.0 \\
\hline 6.5 & 1889 & 664 & 48507 & 1.0 & 0.5 \\
\hline 6.0 & 1344 & 413 & 55963 & 1.0 & 1.0 \\
\hline 5.0 & 760 & 250 & 56710 & 1.0 & 0.5 \\
\hline 4.0 & 404 & 143 & 12000 & 1.0 & 0.5 \\
\hline 3.0 & 173 & 57 & 7500 & 1.0 & 0.05 \\
\hline
\end{tabular}




\begin{tabular}{|l|c|c|c|c|c|}
\hline & 173 & 115 & 7442 & - & 0.05 \\
\hline \multirow{2}{*}{$\mathbf{2 . 0}$} & 56 & 18 & 4200 & 1.0 & 0.02 \\
\hline & 56 & 37 & 4181 & - & 0.02 \\
\hline
\end{tabular}

We perform cooling simulations for particles of diameter 4, 3 and $2 \mathrm{~nm}$ starting from the amorphous state that results from the melting of the corresponding zeolites at higher temperature. Additionally, for the nanoparticle of size of 3 and $2 \mathrm{~nm}$, we carry out the crystallization simulations with silica to SDA ratio 1.51:1. The cooling rate for the crystallization is listed in Table S2.

To assess the thermal stability of a 2 nm silicalite-1, we first create a slab of MFI from the unit cell obtained from the zeolite database, ${ }^{11}$ and remove all the oxygen atoms from the structure. We then cut multiple $2 \mathrm{~nm}$ spheres from the bulk MFI crystal and calculate their degree of condensation (Fig S1). The degree of condensation of a framework is written as $c=1 /{ }_{4} \sum_{n=0}^{4} \mathrm{n} Q^{\mathrm{n}_{12}}$, where $Q^{\mathrm{n}}$ is the fraction of silica with n neighbors.

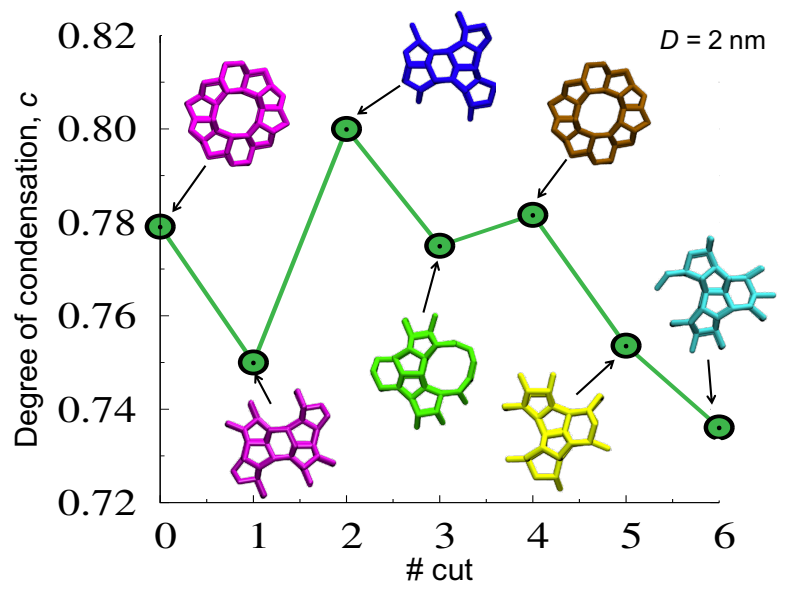

Figure S1. Degree of condensation of spherical silicalite-1 particles cutting differently from the bulk MFI.

We choose as $2 \mathrm{~nm}$ spherical silicalite- 1 the zeolite particle that has one pore and highest degree of condensation (first image in Fig S1), which contains $86 \mathrm{~T}$ particles. We then introduce 5 SDA particles to fill the central pore and 25 more randomly placed using PACKMOL Package ${ }^{13}$ around the surface of the MFI framework. This $2 \mathrm{~nm}$ MFI zeolite (with $86 \mathrm{~T}+30 \mathrm{~S}$ ) is then solvated with 4200 water molecules. We perform two consecutive minimization simulations; first keeping $\mathrm{T}$ particles frozen (by setting a zero force in LAMMPS) but letting water and $S$ move. This allow the $S$ and $\mathrm{W}$ particles to reposition based on the intermolecular interactions keeping $\mathrm{T}$-framework undisturbed. We use the $\mathrm{TS}+\mathrm{W}$ model $^{6}$ for the interactions among the species present in the system. In the subsequent minimization simulation, we relax the box and remove the zero force constrains on $\mathrm{T}$ particles so that the silica framework can adapt the intermolecular distance based in the force field parameters. The minimized structure is then equilibrated at $-13^{\circ} \mathrm{C}$ for $10 \mathrm{~ns}$. This equilibrated structure is then heated 
with a rate of $1{ }^{\circ} \mathrm{C} / \mathrm{ns}$ to a temperature $327^{\circ} \mathrm{C}$. Transformation of MFI to a different isomer along this heating simulation was tracked by calculating degree of condensation, $c$ and visual inspection using VMD. ${ }^{10}$

We compute the degree of condensation of silicalite- 1 nanoslabs of four sizes: a) $4.0 \mathrm{~nm} \times 4.0 \mathrm{~nm} \times$ $1.3 \mathrm{~nm}$, b) $4.0 \mathrm{~nm} \times 2.0 \mathrm{~nm} \times 1.3 \mathrm{~nm}$, c) $2.7 \mathrm{~nm} \times 1.0 \mathrm{~nm} \times 1.3 \mathrm{~nm}$, and d) $1.3 \mathrm{~nm} \times 1.0 \mathrm{~nm} \times 1.3 \mathrm{~nm}$, selected according to those proposed to occur in the nucleation pathway of silicalite- $1 .{ }^{14}$ Following the procedures as indicated above for the spherical particles, we cut the slabs from the bulk MFI crystal structure. For each slab size, we changed the crystallographic axis (three columns in Fig S2) while cutting. The proposed nanoslab structure in $\operatorname{ref}^{19}$ is shown in Fig S2(ii) while the ones presented in ref ${ }^{14}$ are shown in the third column (panel iii, vi, ix, xii). In each panel we mention the number of silica units and their corresponding degree of condensation, $c$. We find that the $c$ values of the nanoslab shown in the third column (along $c$-axis) are the largest compared to others ( $a$ - or $b$-axis), suggesting their highest stability. Hence we present $c$ values corresponding to the structures iii, vi and ix in the main article (Fig 4) to compare them with the degree of condensation of spherical perfect MFI or the compact isomer observed in simulation.

(a)

\begin{tabular}{|l|l|l|}
\multicolumn{1}{|c|}{ Along $b$-axis } & Along a-axis & Along $c$-axis \\
\hline (i) $N_{\mathrm{SiO}_{2}}=392, c=0.801$ & (ii) $N_{\mathrm{SiO}_{2}}=368, c=0.792$ & (iii) $N_{\mathrm{SiO}_{2}}=384, c=0.854$ \\
& &
\end{tabular}

Figure S2. Snapshots of the nanoslabs of different sizes cut from the bulk. Number of silica unit $N_{\mathrm{SiO} 2}$, degree of condensation, $c$ and crystallographic length of each nanoslabs are mentioned in each panel. 
We calculate the fraction of $T$ sites with $n$ number of $T$ first neighbors (i.e., the fraction of $Q^{n}$ species) using a cutoff distance $0.4 \mathrm{~nm}$ that corresponds to the first minimum in the radial distribution function between $\mathrm{T}$ particles. Ring size distributions in the 3 and $2 \mathrm{~nm}$ perfect $\mathrm{Z} 1$ zeolite and their corresponding compact isomers are calculated on a single frame using the code of Matsumoto et al,,$^{15}$ with cutoff distance of $0.4 \mathrm{~nm}$.

Network-accessible Pore Size Distribution (PSD) in zeolites and compact isomers are calculated using PoreBlazer code ${ }^{16}$ ( $\mathrm{PB}$ v4.0) with a probe of size as that of a nitrogen atom with Lennard Jones length-scale parameter $\sigma_{\mathrm{LJ}}=3.314 \AA$. Only single configuration of the perfect $\mathrm{Z} 1$ of size 2 (panel ii in Fig. $1 \mathrm{~b}$ of the main article) and $3 \mathrm{~nm}$ (panel $\mathrm{v}$ in Fig. 1b of the main article) and their corresponding compact isomers (panel iii and vii in Fig. 1b of the main article) are used for the PSD calculation. While calculating PSD, $S$ and $\mathrm{W}$ particles are removed from the pore and only framework particles $(\mathrm{T})$ are considered. $\mathrm{T}$ particles are represented as $\mathrm{Si}$ with interaction parameters; $\sigma_{\mathrm{LJ}}=3.336 \AA$, $\varepsilon_{\mathrm{LJ}}=$ $202.15 \mathrm{~K}$ and molecular weight $m_{\mathrm{Si}}=28.085 \mathrm{u}$ adapted from the default parameter setting of PoreBlazer, except the $\sigma_{\mathrm{LJ}}$. This is decided empirically by matching of the peak position in the PSD of bulk silicalite-1 with the experiment (Fig S3). Since the original PoreBlazer code is for a periodic system, nano-zeolites either in vacuum or immersed in solvent requires renormalization of the PSD by removing the peaks beyond the size of the particle.

As a test case, we generate a bulk silicalite- 1 simulation box from the unit cell given in the zeolite database. ${ }^{11}$ We calculate the PSD of the silica framework using the simulation parameters mentioned above. The PSD obtained from PoreBlazer code is compared with the experimental data shown in Section A.5.

We make use of LAMMPS's "compute $x r d$ " command to compute X-ray diffraction (XRD) ${ }^{17}$ patterns of the crystal. To get the XRD patterns of calcinated zeolites in our simulation, we ignore $S$ and $\mathrm{W}$ particles while calculating XRD, only $\mathrm{T}$ particles are considered and assigned to them the scattering form factors of Si atoms. We use wavelength of incident radiation of $\lambda=1.5406 \AA$ of copper K- $\alpha$ for the calculation of XRD.

\section{A.3. Estimation of Melting temperature in MD Simulations using Structural and Energetic Criteria}

Equilibrium melting of the zeolite particles is identified by the sudden increase in the potential energy $E^{\mathrm{T}}$ of the interation between the $\mathrm{T}$ network former particles with temperature in the heating simulations (Fig. S3a, c). $T_{\mathrm{m}}$ is defined as the inflection point in the slope of $E^{\mathrm{T}}$ versus temperature. We do the same calculation for all zeolite sizes considered in this study. One challenge in estimating $T_{\mathrm{m}}$ at small sizes (especially below $D=4.0 \mathrm{~nm}$ ) is that the change in $E^{\mathrm{T}}$ becomes less sharp (Fig. S3c). Hence, we also need to track the structural collapse of the ordered porous structure of zeolite $\mathrm{Z} 1$ as it melts. We do that by calculating the fraction of $Q^{n}$ species along the heating trajectory. In Fig. $S 3 b, d$ we present the change of the fraction of $Q^{\mathrm{n}}$ species with temperature for $8 \mathrm{~nm}$ and $3 \mathrm{~nm}$ nanozeolites. We observe that $Q^{4}$ decreases significantly upon melting, whereas the value of $Q^{3}$ increases. 

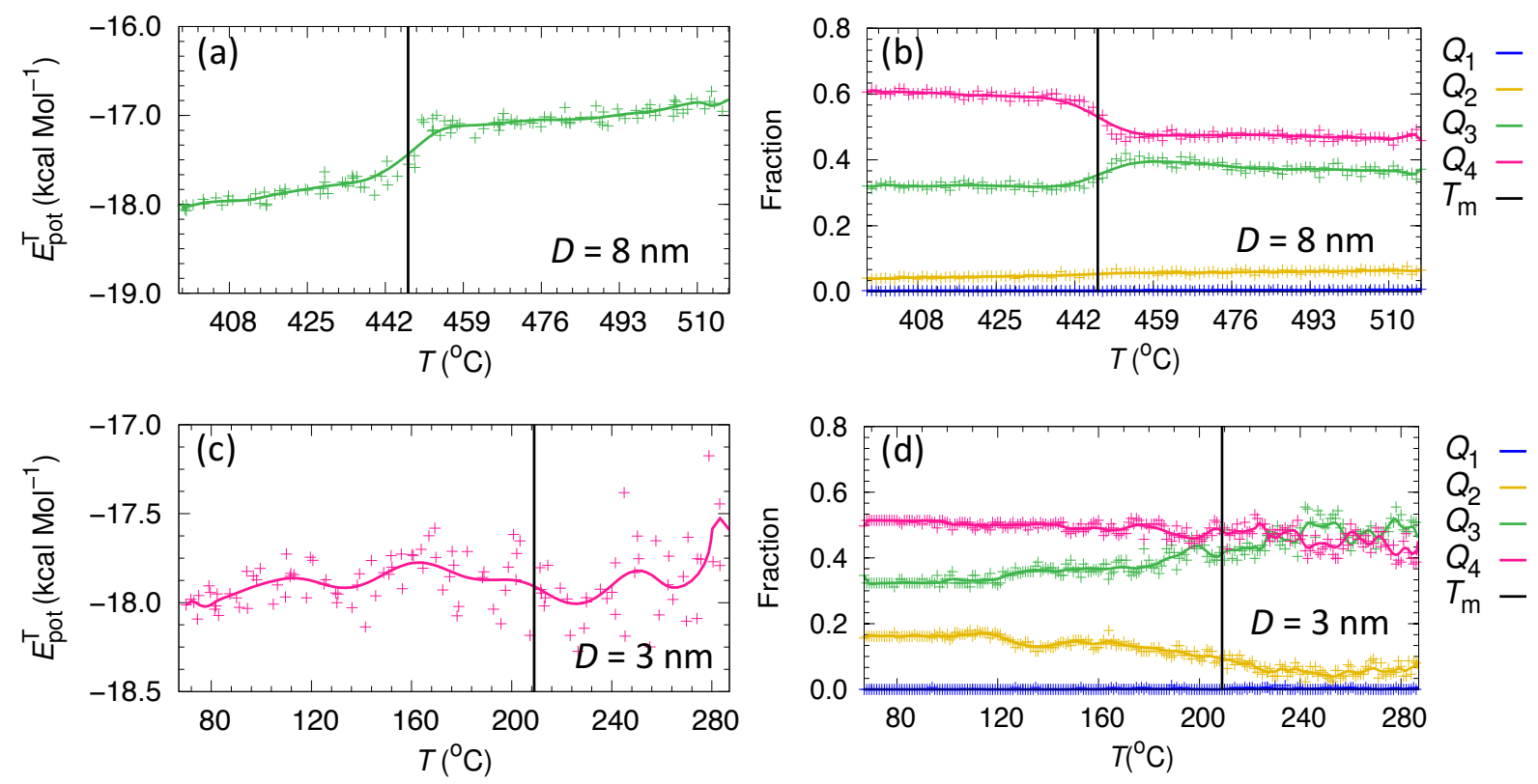

Figure S3. How the energy per $\mathrm{T}$ particle and local coordination number (presented in terms of $Q^{\mathrm{n}}$ ) of $\mathrm{T}$ particles changes during the melting of (a-b) $8 \mathrm{~nm}$ and (c-d) $3 \mathrm{~nm}$ particle. The vertical line represents the $T_{\mathrm{m}}$ for that particular size. Points are the actual data and line is the fitting of the data by a Bezier curve of degree $n$, with $n$ being the number of datapoints.

Likewise, we identify the non-equilibrium crystallization of the zeolite from the amorphous phase by the sudden decrease in the potential energy with temperature as well as the emergence of the typical ordered porous structure of zeolite $\mathrm{Z} 1$ quantified using $Q^{\mathrm{n}}$.

\section{A.4. Evaluation of Framework Energies of BEA, MFI and Z1 Zeolites}

To evaluate the energy of Silicalite-1 and BEA in our model we use a simulation box with $3 \times 3 \times 3$ unit cells of the crystal structure (which corresponds to 2591 silica units for Silicalite-1 and 1728 for BEA) and minimize its energy using LAMMPs software, allowing the box to relax. The unit cells are obtained from the zeolite databas $\mathrm{e}^{11}$, which we remove the oxygen atoms and treat the position of the silicon atoms as the ones of our coarse-grained silica units ( $\mathrm{T}$ particles). No SDA or water molecules are present in the simulation box while evaluating the framework energies. We obtain the energy of BEA as $96.19 \mathrm{~kJ} \mathrm{~mol}^{-1}$ and the one of Silicalite- 1 as $-97.40 \mathrm{~kJ} \mathrm{~mol}^{-1}$. We minimize the energy of $\mathrm{Z} 1$ crystal without SDA (only $\mathrm{T}$ particles) and find the energy to be $-92.26 \mathrm{~kJ} \mathrm{~mol}^{-1}$. The difference in energy between Silicalite- 1 and $\mathrm{Z1}$ is $-5.14 \mathrm{~kJ} \mathrm{~mol}^{-1}$. The use of SDA in the formation of $\mathrm{Z} 1$ helps stabilize this crystal in the TS+W model. A mixture of $74 \%$ of $\mathrm{T}$ particles with $26 \%$ of $S$ particles $\left(X_{\mathrm{T}}=0.74\right)$ produces a perfect crystal with energy of $-141.29 \mathrm{~kJ} \mathrm{~mol}^{-1}$ per mole of silica units, much more stable than the empty crystals.

\section{A.5. Verification of Pore Size Distribution (PSD) Analysis with Experimental Data of Silicalite-1}

We verify the pore size distribution obtained from PoreBlazer code ( $\mathrm{PB} v 4.0)^{16}$ by comparing with the experimental data of silicalite- $1 .{ }^{18}$ Calculated pore size distribution is slightly broad but the mean pore 
diameter $(0.48-0.54 \mathrm{~nm})$ is consistent (Fig. S4) with the experimental results obtained from nitrogen sorption study.
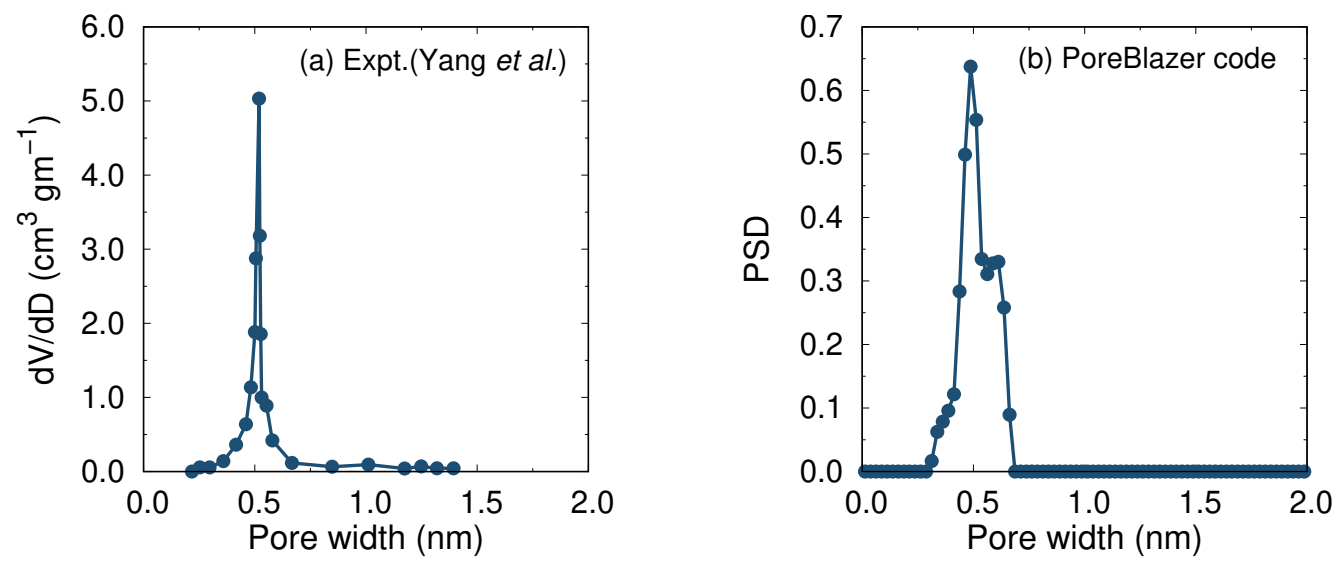

Figure S4. Pore size distribution of bulk silicalite-1 in (a) experiment ${ }^{18}$ and in (b)calculation using PoreBlazer code of Ref. ${ }^{16}$

\section{B. Supporting Results}

\section{B.1. Transformation of $2 \mathrm{~nm}$ Zeolite to a Compact Isomer}

Upon heat treatment $2 \mathrm{~nm}$ zeolite transforms to a compact isomer presented in Fig. S5.

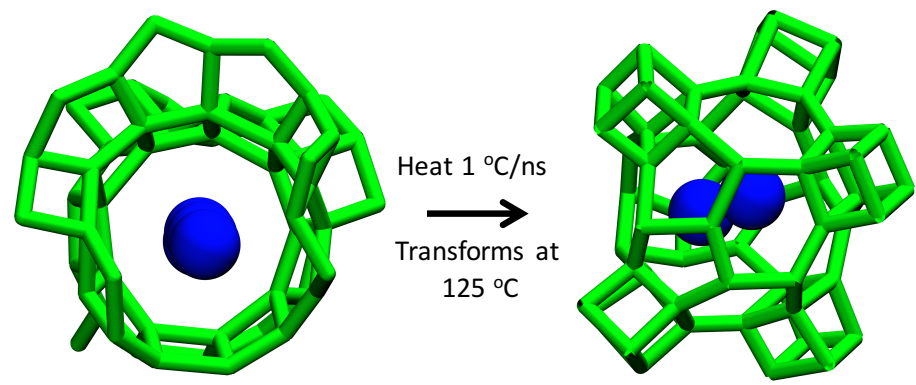

Figure S5. Conversion of $2 \mathrm{~nm}$ zeolite $\mathrm{Z} 1$ into another stable isomeric form while heating. Green stick represents sililica-like $\mathrm{T}$ particles and blue spheres are the SDA (S).

\section{B.2. Silica speciation $Q^{n}$ and the degree of condensation, $c$ of Perfect Zeolite as well as of the crystallized particles.}

We investigate the structural compactness of the nanocrystal obtained for different sizes by comparing the ratio of different $Q^{\mathrm{n}}$ species to the perfect Z1. In Fig. S6a-d we show that although $Q_{Z 1}^{4} / Q_{\mathrm{crystal}}^{4}$ and $Q_{Z 1}^{3} / Q_{\text {crystal }}^{3}$ do not change much with the change in the size of the particles, $Q_{Z 1}^{2} / Q_{\text {crystal }}^{2}$ and $Q_{Z 1}^{1} / Q_{\text {crystal }}^{1}$ sharply go up below $4 \mathrm{~nm}$ diameter. This suggests that the compact isomers are made up of $Q^{3}$ and $Q^{4}$ species with very little amount of $Q^{1}$ and $Q^{2}$ (Fig S6f-g). More quantitatively, the ratio of 
the degree of condensation $c$ between a perfect $\mathrm{Z} 1$ and the final crystal (Fig. S6e) shows a deviation from 1 for particles below $4 \mathrm{~nm}$ because the recrystallized $\mathrm{Z} 1$ particles reconstruct their surface to attain higher condensation. We note that the crystallized $\mathrm{Z} 1$ for $3 \mathrm{~nm}$ size (panel vi in Fig. $1 \mathrm{~b}$ of the main article) with lower silica to SDA ratio is slightly more compact than the perfect Z1 (panel $v$ in Fig. $1 \mathrm{~b}$ of the main article) but less compact than its other isomer (panel vii in Fig. 1b of the main article). We suggest that the appearance of isomers can be evaluated in experiments by ${ }^{29} \mathrm{Si}$ nuclear magnetic resonance (NMR) technique.
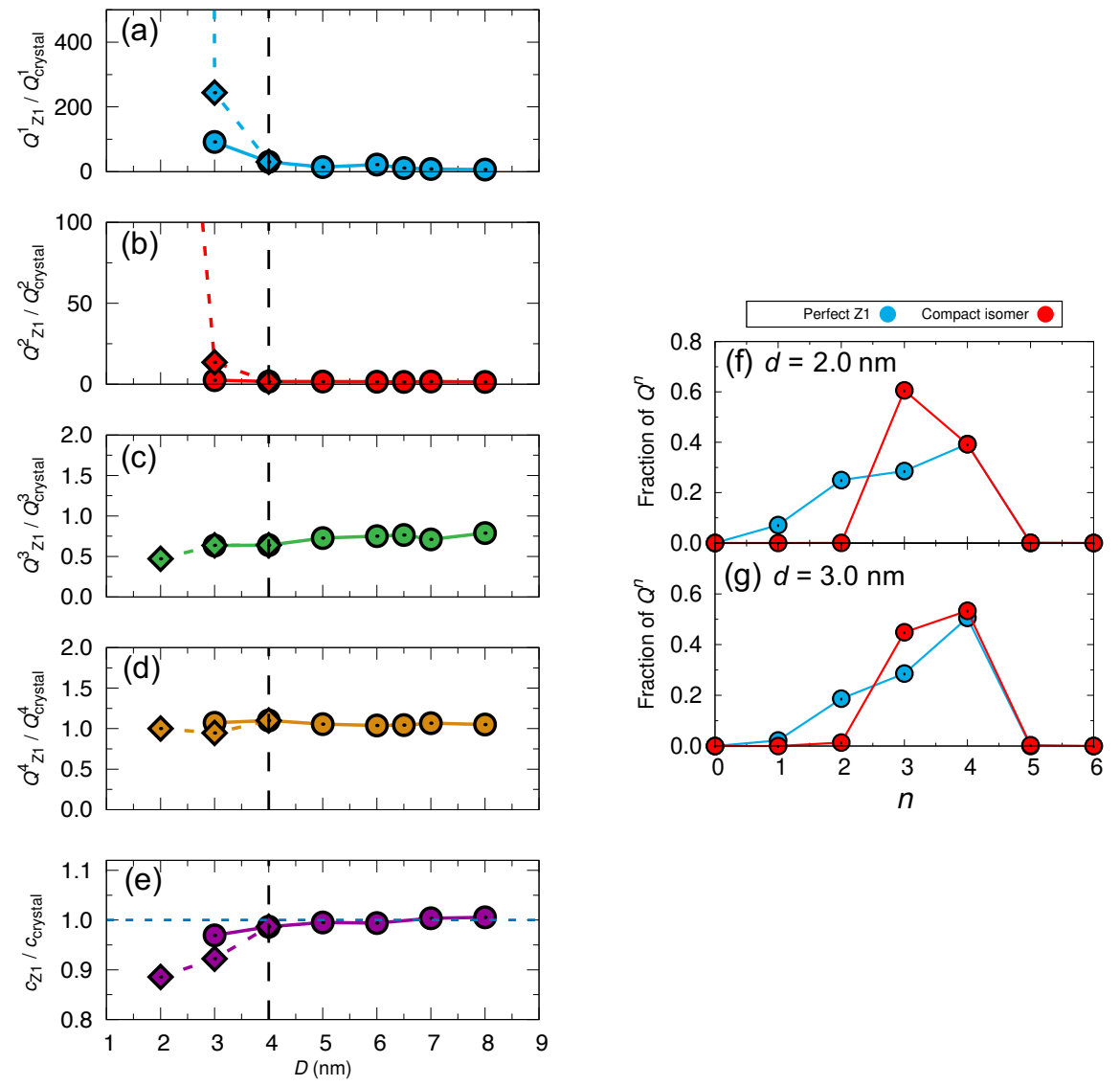

Figure S6. Analysis of the compactness of the crystalized structures as compared to the perfect zeolite of same size. (a-d) the ratio of speciation of silica, $Q^{\mathrm{n}}$ of perfect zeolite with respect to the species formed after crystallization (Cirlce: crystallized zeolite, Cubes: compact isomer). (e) Degree of condensation of zeolite with respect to the crystal formed. ( $\mathrm{f}-\mathrm{g}$ ) $\mathrm{Q}^{\mathrm{n}}$ fraction of individual 2 and $3 \mathrm{~nm}$ isomer is compared with their corresponding perfect zeolite. 


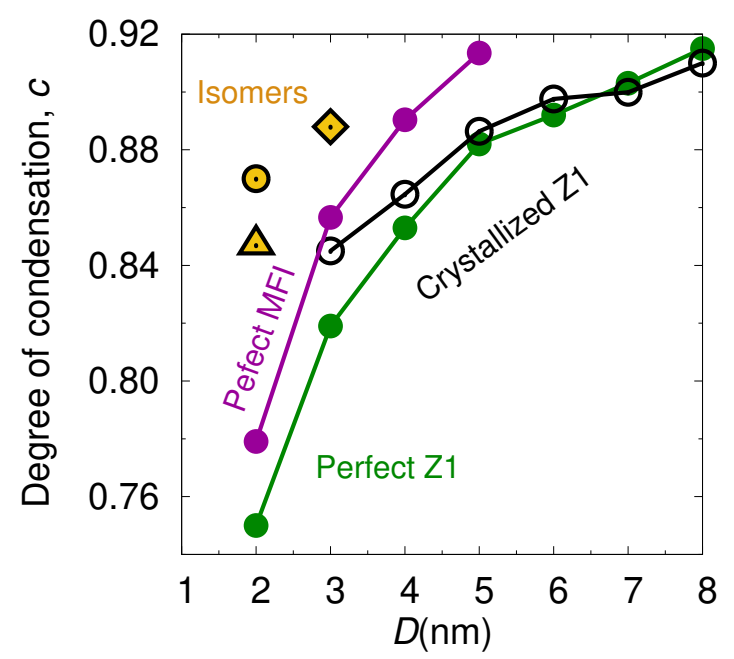

Figure S7. Degree of condensation, $c$ of ordered structures as a function of particle diameter. Magenta circles show $c$ of perfectly cut zeolite MFI, green circles of perfect Z1 and black circles for Z1 crystallized from solution. Yellow triangle and cube present $c$ values of the compact isomers obtained from a zeolite Z1of size 2 and $3 \mathrm{~nm}$ respectively, whereas the one obtained from $2 \mathrm{~nm}$ MFI is presented with yellow circle.

\section{B.3. XRD of the Compact Isomers at Small Sizes as Compared to the Perfect Zeolites of Same size}

In Fig. S8a-b we present X-ray diffraction (XRD) patterns obtained from compact isomer and corresponding zeolite $\mathrm{Z} 1$ of sizes 3 and $2 \mathrm{~nm}$ respectively. We first confirm that $3 \mathrm{~nm}$ crystal obtained using higher silica to SDA ratio is a zeolite Z1 from its similar XRD pattern (Fig. S8a) as that of a perfectly cut $3 \mathrm{~nm} \mathrm{Z1}$. Upon comparison between the perfect zeolite and the compact isomer we see a difference in ordering (peaks at high $2 \theta$ angle).
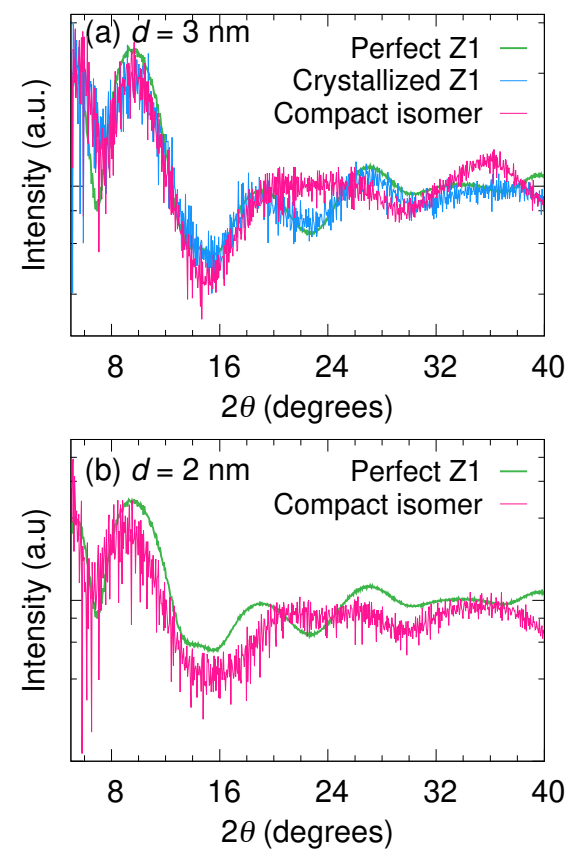

Figure S8. XRD of (a) $3 \mathrm{~nm}$ and (b) $2 \mathrm{~nm}$ perfect zeolite and their corresponding crystallized isomers. 


\section{References:}

1. Navrotsky, A.; Trofymluk, O.; Levchenko, A. A., Thermochemistry of Microporous and Mesoporous Materials. Chemical Reviews 2009, 109 (9), 3885-3902.

2. Piccione, P. M.; Woodfield, B. F.; Boerio-Goates, J.; Navrotsky, A.; Davis, M. E., Entropy of Pure-Silica Molecular Sieves. The Journal of Physical Chemistry B 2001, 105 (25), 6025-6030.

3. Richet, P.; Bottinga, Y.; Denielou, L.; Petitet, J. P.; Tequi, C., Thermodynamic properties of quartz, cristobalite and amorphous SiO2: drop calorimetry measurements between 1000 and $1800 \mathrm{~K}$ and a review from 0 to $2000 \mathrm{~K}$. Geochimica et Cosmochimica Acta 1982, 46 (12), 2639-2658.

4. Zhdanov, S. P.; Feoktistova, N. N.; Kozlova, N. I.; Piryutko, M. M., Silicalites and their thermal stability. Bulletin of the Academy of Sciences of the USSR, Division of chemical science 1985, 34 (12), 2467-2472.

5. Johnson, G. K.; Tasker, I. R.; Howell, D. A.; Smith, J. V., Thermodynamic properties of silicalite SiO2. The Journal of Chemical Thermodynamics 1987, 19 (6), 617-632.

6. Dhabal, D.; Bertolazzo, A. A.; Molinero, V., Coarse-Grained Model for the Hydrothermal Synthesis of Zeolites. The Journal of Physical Chemistry C 2021, 125 (48), 26857-26868.

7. Molinero, V.; Moore, E. B., Water Modeled As an Intermediate Element between Carbon and Silicon. The Journal of Physical Chemistry B 2009, 113 (13), 4008-4016.

8. Stillinger, F. H.; Weber, T. A., Computer simulation of local order in condensed phases of silicon. Physical Review $B$ 1985, 31 (8), 5262-5271.

9. Plimpton, S., Fast Parallel Algorithms for Short-Range Molecular Dynamics. Journal of Computational Physics 1995, $117(1), 1-19$

10. Humphrey, W.; Dalke, A.; Schulten, K., VMD: Visual molecular dynamics. Journal of Molecular Graphics 1996, 14 (1), 33-38.

11. Baerlocher, C.; McCusker, L. B. Database of Zeolite Structures. http://www.iza-structure.org/databases/.

12. Devreux, F.; Boilot, J. P.; Chaput, F.; Lecomte, A., Sol-gel condensation of rapidly hydrolyzed silicon alkoxides: A joint 29Si NMR and small-angle x-ray scattering study. Physical Review A 1990, 41 (12), 6901-6909.

13. Martínez, L.; Andrade, R.; Birgin, E. G.; Martínez, J. M., PACKMOL: A package for building initial configurations for molecular dynamics simulations. Journal of Computational Chemistry 2009, 30 (13), 2157-2164.

14. Kirschhock, C. E.; Buschmann, V.; Kremer, S.; Ravishankar, R.; Houssin, C. J.; Mojet, B. L.; van Santen, R. A.; Grobet, P. J.; Jacobs, P. A.; Martens, J. A., Zeosil Nanoslabs: Building Blocks in nPr4N+-Mediated Synthesis of MFI Zeolite. Angew. Chem. Int. Ed. 2001, 40 (14), 2637-2640.

15. Matsumoto, M.; Baba, A.; Ohmine, I., Topological building blocks of hydrogen bond network in water. The Journal of Chemical Physics 2007, 127 (13), 134504.

16. Sarkisov, L.; Bueno-Perez, R.; Sutharson, M.; Fairen-Jimenez, D., Materials Informatics with PoreBlazer v4.0 and the CSD MOF Database. Chemistry of Materials 2020, 32 (23), 9849-9867.

17. Coleman, S. P.; Spearot, D. E.; Capolungo, L., Virtual diffraction analysis of $\mathrm{Ni}\left[\begin{array}{ll}0 & 10\end{array}\right]$ symmetric tilt grain boundaries. Modelling and Simulation in Materials Science and Engineering 2013, 21 (5), 055020.

18. Yang, X.; Huang, L.; Li, J.; Tang, X.; Luo, X., Fabrication of SiO2@silicalite-1 and its use as a catalyst support. RSC Advances 2017, 7 (20), 12224-12230.

19. Ravishankar, R.; Kirschhock, C. E. A.; Knops-Gerrits, P.-P; Feijen, E. J. P.; Grobet, P. J.; Vanoppen, P.; Schryver, F. C. D.; Miehe D.; Fuess, H.; Schoeman, B. J.; Jacobs, P. A.; Martens, J. A., Characterization of Nanosized Material Extracted from Clear Suspensions for MFI Zeolite. J. Phys. Chem. B 1999, 103, 4960-4964. 